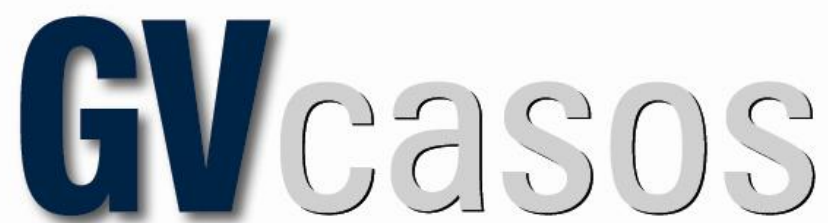

Volume 8

Número 1

Jan/Jun 2018

Doc. 6

Rev. Bras. de Casos de Ensino em Administração

ISSN 2179-135X

DOI: http://dx.doi.org/10.12660/gvcasosv8n1c6

\title{
HOMENS EM ARMAS: A TRAJETÓRIA DO POLICIAL CIVIL PARA ANÁLISE SOBRE VIDA, ORGANIZAÇÃO E PODER
}

Men in guns: The trajectory of a policeman to analyze life, organization and power

RODRIGO GUIMARÃES MOTTA - rodrigo-motta@uol.com.br

Pontifícia Universidade Católica de São Paulo - São Paulo, SP, Brasil

MARia AMÉlia JUNDURian CoRÁ - mcora@ pucsp.br

Pontifícia Universidade Católica de São Paulo - São Paulo, SP, Brasil

Submissão: 05/01/2018 | Aprovação: 21/02/2018

\section{Resumo}

Maruan, quando criança, sonhou em ser policial e, quando adulto, prestou concurso e entrou na Polícia Civil. Ao longo de sua carreira, ocupou diversas posições nessa instituição, no GOE, GER, Garra e em delegacias de polícia. Sua trajetória foi marcada por diversas disputas de poder, com superiores e pares de trabalho que influenciaram suas escolhas dentro da organização e também contribuíram para gerar significado em seu trabalho para o indivíduo.

Palavras-chave: Estudos Críticos da Administração, Foucault, organizações, poder, polícia.

\begin{abstract}
Maruan in his childhood dreamt about being a policeman. When he got the chance, he was approved and joined the police. There he worked in several departments, such as GOE, GER and GARRA and in the police station. His career was marked by several power conflicts, with his superiors and peers, that had an influence in his professional choices and also in the development of the significance of his work to himself.
\end{abstract}

Keywords: Critical Management Studies, Foucault, organizations, power, police.

\section{Introdução}

A polícia é imprescindível para o funcionamento da sociedade moderna. Quem escolhe esse trabalho desempenha uma função necessária, mas que envolve riscos, pelo tipo de situações que devem ser enfrentadas, e também desgastes emocionais e físicos. A profissão de policial é marcada por muitas contradições, sendo a representação desde aqueles que garantem a segurança até aqueles que são violentos ou até mesmo corruptos. Este caso de ensino, ao retratar a vida de um policial com esses dilemas, demonstra como estes se tornam mais complexos ao considerar as relações de poder que permeiam a trajetória profissional desses agentes.

$\mathrm{O}$ caso de ensino tem como objetivo incentivar os professores e estudantes a refletir sobre o trabalhador nas organizações em geral e a Polícia Civil em particular, sob uma perspectiva crítica, diferente daquela que predomina nos estudos organizacionais, onde são privilegiadas, abordagens funcionalistas. Para este caso de ensino, foi eleita a analítica do poder de Michel Foucault para ser utilizada como pilar para essa análise.

Este caso de ensino retrata a história de vida do policial Maruan, em que, durante sua trajetória profissional, as disputas de poder ficam marcadas e passam a significar a carreira do policial, trazendo de maneira contínua uma reflexão sobre qual seu papel na organização e como o jogo de poder influencia sua carreira e, com isso, as tomadas de decisão. O caso concentra-se na vida 
HOMENS EM ARMAS: A TRAJETÓRIA DO POLICIAL CIVIL PARA ANÁLISE SOBRE VIDA...

Rodrigo Guimarães Motta, Maria Amélia Jundurian Corá

de Maruan e nas pessoas mais próximas a ele, que são seus familiares: pais, irmãos, a esposa, Renata, seus dois filhos e também os policiais com quem Maruan conviveu em algum momento de sua carreira e que tiveram influência nela: Antônio (Academia de Polícia e GER), Adalberto e Rafael (GOE), Tássio e Manoel (GER) e José e Maricy (delegacia).

\section{O sonho de ser policial}

Maruan cresceu em um bairro de classe média na Zona Oeste de São Paulo. Filho de pai microempresário e mãe dona de casa, tem dois irmãos mais velhos: um se tornou engenheiro e a irmã, fisioterapeuta. Durante a infância, na década de 1980, passava a maior parte do tempo brincando com seus amigos de rua no quintal de casa ou principalmente na rua onde morava. Esta, por ser muito movimentada, frequentemente era cenário de viaturas policiais que a atravessavam em alta velocidade, sirene ligada, rumo a uma ocorrência na região. Foi ao assistir a passagem das viaturas que Maruan decidiu ser policial. A criança se encantou com os uniformes, com as armas, com as viaturas. Ele queria ser um herói, salvar vidas, proteger pessoas inocentes e ter da sociedade a admiração que não sentia em seu pai, talvez em função de ser uma pessoa muito séria e introspectiva, que vivia apenas para o seu pequeno negócio, o qual sempre passava por dificuldades. Quanto a sua mãe, submissa ao pai, concordava com as colocações dele. Maruan não se identificava com seus irmãos e sentia-se perseguido e discriminado pelos pais.

$\mathrm{Na}$ adolescência, Maruan, que era conhecido por todos como sendo muito valente, despertou a atenção do pai de Cristiano, seu amigo, que era treinador de boxe no clube local. Logo, Maruan foi convidado para treinar boxe, e demonstrou talento e uma persistência extraordinária. Treinava todos os dias, de domingo a domingo. No final de um ano, começou a participar de competições e chegou a ser campeão estadual. Daí passou a sonhar em participar dos Jogos Olímpicos. Sua família, após alguma hesitação, o apoiou. Os irmãos mais velhos ajudariam os pais com o orçamento doméstico até as seletivas olímpicas. Maruan teria quatro anos para se preparar com dedicação exclusiva para realizar seu sonho. E Maruan se preparou como poucos já se prepararam antes. Treinava e competia todos os dias. Se alimentava de maneira regrada, estudava os adversários. Ele fez absolutamente tudo o que podia. Enquanto seguia essa espartana rotina de treinos, foi aprovado no vestibular e cursou a faculdade de Letras. Aproveitou para participar dos campeonatos universitários.

Tinha uma relação melhor com os pais e com os irmãos, mas se sentia deslocado, como se aquilo que o interessava, as histórias dos policiais heróis que continuava a acompanhar e o esporte, fosse algo desconectado da dura realidade que sua família enfrentava, sempre preocupada em pagar as contas no final do mês, com pouco espaço para o lazer, a descontração e as conversas triviais. Interesses muito diversos os separavam.

Infelizmente para Maruan, na sua categoria, havia pelo menos cinco outros jovens, quase tão dedicados quanto ele, porém muito mais talentosos. Ele participou das seletivas para os Jogos Olímpicos e perdeu. Nunca deixou de treinar boxe, mas aceitou o fato de que jamais chegaria aos Jogos Olímpicos. Com o diploma da faculdade, foi procurar emprego. Sua família o apoiou, mas mesmo esse apoio machucou o jovem. Sua mãe disse, em certa ocasião, o que, para Maruan, todos na sua casa pensavam: "Agora deixe essa bobagem de esporte de lado e vá ganhar o seu dinheiro, como os seus irmãos".

Tinha 20 anos e trabalhou em várias empresas em cargos administrativos, em escolas, como professor, e também em Vendas, em lojas de centros comerciais. Sempre muito mal remunerado, quando seu pai ficou doente e fechou o negócio, Maruan viu que tinha que buscar um emprego mais estável e mais bem remunerado para auxiliar seus irmãos, que já eram casados e tinham suas próprias famílias, a sustentar seus idosos pais. Foi então que Maruan decidiu combinar essa necessidade com o antigo sonho de ser policial.

À noite, após o trabalho, estudava para concursos. Nos primeiros anos, foi reprovado, porém, no segundo ano, foi aprovado como escrevente do Tribunal de Justiça. Enquanto trabalhava lá, 
HOMENS EM ARMAS: A TRAJETÓRIA DO POLICIAL CIVIL PARA ANÁLISE SOBRE VIDA...

Rodrigo Guimarães Motta, Maria Amélia Jundurian Corá

continuou estudando para o concurso para a polícia. Finalmente, após quatro anos tentando, Maruan foi aprovado para a Polícia Civil. No primeiro dia de Academia de Polícia, ele foi o primeiro a chegar. Estava ansioso e animado com o seu novo trabalho. Finalmente realizaria seu sonho de infância.

Para sua família, essa conquista proporcionou uma sensação de alegria, pois as despesas seriam distribuídas de modo mais razoável entre os irmãos. Porém, novamente sua mãe expressou uma restrição: "Essa profissão não paga tão bem, e você ainda vai colocar sua vida em risco. Por que não encontra um emprego como o dos seus irmãos?”. Aquilo o entristeceu, mas também fez aumentar a sua vontade de se destacar no trabalho de policial, para, quem sabe, ser aceito pela sua família.

\section{A Academia de Polícia}

Maruan e os 60 novos policiais civis que entraram com ele começaram sua trajetória na Academia de Polícia, localizada no bairro do Butantã, ao lado da Universidade de São Paulo. Nenhum deles tinha experiência com o uso de armas ou com qualquer outra das habilidades necessárias para o desempenho de sua nova profissão. Naquele momento, ele percebeu que o tempo de formação dos novos policiais seria de apenas seis meses, e que dificilmente ele se capacitaria para uma profissão tão complexa em tempo tão exíguo. Mais perplexo ele ficou ao saber que os escrivães da Polícia Civil, que se interessavam em ser agentes policiais e se juntaram a eles na Academia, por já serem policiais, mesmo que exercessem apenas atividades burocráticas, cursariam apenas um mês de Academia (ao longo de sua carreira, Maruan veria esse tempo ser reduzido muitas vezes, dadas a falta de recursos da polícia e a necessidade de mais policiais nas ruas. Atualmente, um profissional recém-ingressado na polícia cursa apenas quatro meses de Academia).

Realmente, Maruan não se capacitou o suficiente para exercer sua profissão em seis meses, mas recebeu um conselho de seu professor preferido, Antônio, o qual o auxiliaria muito nos 15 anos seguintes. Ao confidenciar para esse professor sua insegurança em função do escasso treinamento recebido, Antônio lhe respondeu: "Na polícia, você deve aprender a contar apenas com você para progredir ou mesmo para ficar vivo. No máximo, seus amigos e colegas mais próximos poderão prestar algum auxílio. Do governo, da Secretaria de Segurança Pública, da chefia, espere apenas injustiças. É assim que se joga o jogo". Essas palavras o impressionaram muito, porém seus sonhos ainda estavam muito vivos em sua mente, e ele decidiu não prestar maior atenção a essas palavras. Mas, como veria mais para a frente, o próprio Antônio logo seria uma das pessoas com quem ele poderia contar.

Um outro ponto que o incomodou durante sua formação foi que diversas pessoas, amigos de sua família e vizinhos, ao saberem que ele havia ingressado na polícia, começaram a se afastar dele e de sua família. Ninguém dava maiores explicações, mas era evidente que essas pessoas não queriam ter nenhum tipo de vínculo com um policial. Pior ainda eram os mais ousados, que faziam brincadeiras e comentários depreciativos, como a proprietária da padaria onde a mãe de Maruan comprava pão todos os dias, de nome Débora.

Sempre que Maruan passava em frente àquele comércio, Débora, uma senhora com 50 anos, baixa e um pouco obesa, o cumprimentava e logo emendava: "Quando sair da delegacia, só não venha roubar aqui da padaria, que eu não vendo mais para sua mãe, hein?". Todas as vezes que isso acontecia, ele se sentia humilhado, ainda que o tom fosse de brincadeira. Ignorava Débora, mas passava horas pensando por que ela tinha uma impressão tão negativa da polícia. Com o passar do tempo, entenderia melhor os motivos de Débora. Ele se entristecia, porque esses comentários eram feitos também para seus pais e irmãos, que, ainda que não contassem tudo o que ouviam para ele, às vezes deixavam escapar algo depreciativo sobre o seu trabalho que haviam ouvido de alguém próximo. 
HOMENS EM ARMAS: A TRAJETÓRIA DO POLICIAL CIVIL PARA ANÁLISE SOBRE VIDA...

Rodrigo Guimarães Motta, Maria Amélia Jundurian Corá

Finalmente, chegou o dia da formatura. Após receberem os cumprimentos protocolares, os novos policiais foram informados de que todos eles trabalhariam em Campinas, em uma tropa de elite da Polícia Civil, o GOE. Maruan pensou por um instante que era algo estranho jovens recémformados na Academia serem designados para uma equipe que deveria ser composta apenas pelos melhores policiais. Mas a criança que se encantava com as sirenes na Zona Oeste logo falou mais alto em sua mente. Ele finalmente realizaria o seu sonho, ir para as ruas, enfrentar foras da lei e ser um dos condutores das viaturas policiais. E ainda conseguiria isso ao mesmo tempo que auxiliaria seus pais com as despesas domésticas. Era isso que importava, não era necessário se preocupar com detalhes. Sair de sua casa também seria algo bem-vindo naquele momento, pois ele não teria que enfrentar as tensões familiares todos os dias.

\section{O GOE}

O GOE é o "Grupo de Operações Especiais", um time que não está vinculado a nenhuma delegacia, porém, quando policiais civis alocados em qualquer uma destas necessitam de apoio fortemente armado para alguma ação, podem acionar o GOE. Os policiais desse grupo usam a farda toda preta e um impressionante colete à prova de balas, com o tipo sanguíneo do policial impresso no peito. Para os novatos e para a população em geral, um integrante do GOE é alguém preparado para tudo. Um herói. Esses foram os primeiros heróis com que Maruan trabalharia ao longo dos próximos anos.

Logo na sua primeira semana, foi solicitada uma viatura do GOE para apoiar uma operação contra traficantes de drogas pesadamente armados em uma favela da região. Maruan, que havia sido designado para trabalhar com um experiente policial, Adalberto, se dirigiu para a viatura rapidamente. Adalberto assumiu o volante e se encaminharam para a favela. Junto com eles foi Rafael, outro novato.

Trânsito intenso, ambos armados; enquanto Maruan estava muito agitado, seu parceiro permanecia concentrado ao volante. Ao estacionar, enquanto Maruan e Adalberto saíam do carro, Rafael assumiu o volante e permaneceu na viatura. Tanto ele quanto Maruan obedeciam às ordens do policial mais experiente. Ao entrar na favela, Adalberto, que conhecia muito bem a região, ao contrário dos outros dois, que jamais haviam estado lá antes, correu para uma rua menos movimentada. Já ouviam os tiros a distância, enquanto os dois avançavam. Após 400 metros, encontraram três traficantes armados com fuzis, virados para o lado oposto. Aos gritos, Adalberto disse para os três se renderem. Um saiu correndo, enquanto os outros dois largaram as armas e se deitaram.

Adalberto disse para Maruan cuidar desses dois, enquanto ele iria atrás do fugitivo. Sozinho, Maruan manteve a arma apontada para os dois traficantes, enquanto percebia que os tiros continuavam em outra parte da favela e que muitas pessoas, que ele não sabia se eram moradores ou cúmplices dos traficantes, se aproximaram dele. A tensão ficou insuportável. O que deveria ele fazer? Suando em seu uniforme preto do GOE, foi com alívio que, após alguns minutos, que pareceram horas, Adalberto voltou sozinho. Tranquilamente, Adalberto novamente retomou o comando, e ele levaram os dois traficantes para a viatura onde Rafael esperava, suando tanto quanto Maruan.

Adalberto riu, disse que os dois tinham ido muito bem, mas para Maruan algo não estava certo. Em seu primeiro trabalho de campo, subira a uma favela desconhecida, apontara a arma para criminosos, ficara sozinho com eles e cercado por pessoas que poderiam ser amigas deles. Definitivamente, não estava preparado para isso. Na semana seguinte, ao comentar seu desconforto com Adalberto, ele concordou, mas disse que era assim que as coisas aconteciam. Mais tarde, essa sensação incômoda aumentaria, quando Rafael, que o acompanhou nesse primeiro dia, foi preso pela Corregedoria por ter atirado e matado duas pessoas que se aproximaram dele em uma ação em outra favela. Como se averiguou depois, estavam ambas desarmadas. 
HOMENS EM ARMAS: A TRAJETÓRIA DO POLICIAL CIVIL PARA ANÁLISE SOBRE VIDA...

Rodrigo Guimarães Motta, Maria Amélia Jundurian Corá

Com o tempo, na prática e sempre correndo riscos, Maruan adquiriu a experiência necessária para desempenhar suas funções no GOE com eficiência. Para isso, muito valeu o fato de ele ter Adalberto como parceiro. Policial experimentado, que gostava do que fazia, tratava de maneira paternalista o jovem policial e o orientava e apoiava em todas as ações.

Algo que não melhorou em seu tempo do GOE, todavia, foi a inadequação dos equipamentos para trabalho. Da mesma forma que, em sua primeira ação policial, ele tivera de enfrentar criminosos armados com fuzis, enquanto ele e os colegas de viatura utilizavam apenas os armamentos convencionais oferecidos pela polícia, em muito inferiores aos daqueles utilizados em especial pelos integrantes do crime organizado.

O que era pior era o que acontecia com os policiais feridos em ação. Além de afastados dos trabalhos, eles perdiam parte de sua remuneração, que já era reduzida (apesar de ser um concurso destinado àqueles com curso superior, na prática, o salário era o equivalente a um concursado com nível secundário). Essa realidade tornava os integrantes do GOE mais duros, sabiam que lutavam não só pela lei e pela ordem, mas também para se manterem íntegros e assegurarem o mínimo de dignidade para si e para suas famílias. Maruan vivia essa rotina quando soube que seu antigo professor preferido, Antônio, havia sido promovido para ser o novo chefe do GER. Se havia um grupo em toda a Polícia Civil que superava o GOE em fama, este era o GER. Maruan, quando comentou a novidade com Adalberto, ouviu como resposta: "Se você quer um dia trabalhar no GER, vá falar com o Antônio. Se não for dessa forma, você nunca conseguirá. Aproveite, garoto". Maruan respirou fundo e, no dia seguinte, foi procurar seu antigo professor. Se era assim que as coisas funcionavam, ele estava disposto a arriscar.

\section{O GER}

O GER é o "Grupo Especial de Resgate", e foi criado para auxiliar a Delegacia Antissequestro em crimes dessa natureza, onde fosse necessário o resgate de reféns, em um momento onde aconteciam muitos sequestros em São Paulo, muitas vezes dezenas simultaneamente. Uma vez que seus membros eram muito bem treinados, o GER passou também a ser utilizado em ações táticas contra criminosos de alto risco, como cumprimento de mandados de prisão e de busca e apreensão e operações contra o crime organizado. Apenas policiais da mais alta competência, provada em outros grupos de elite e muito bem recomendados, fazem parte do GER. Maruan, que não era especialmente experiente, foi bem aceito por Antônio. O novo chefe do GER fora indicado para esse posto pela amizade que tinha com o diretor da Polícia Civil, que fora seu colega de Academia muitos anos atrás. Sabia que os agentes do GER tinham muita autonomia e não respeitavam qualquer chefe, então tratou de levar consigo para lá Maruan, afinal já teria pelo menos um aliado, um jovem, de quem ele conhecia o potencial e o bom trabalho que já havia realizado no GOE, e que o respeitava e admirava pelos tempos de Academia.

No seu primeiro dia, estava visivelmente emocionado. Em pouco mais de um ano na polícia, ele estava junto das lendas da Polícia Civil, os policiais mais experientes e capacitados entre todos. Ao se apresentar, encontrou policiais na faixa entre 30 e 40 anos, com roupas de grife, que mais pareciam executivos bem-sucedidos vestidos de modo casual do que policiais duros e experimentados nas piores situações possíveis. Foi ignorado pelos veteranos, mas também não deixou de olhar com desprezo para eles. Certamente esses playboys não poderiam se equiparar a ele para enfrentar bandidos.

Logo na primeira ocorrência da qual participou, Maruan acompanhou o mais experiente entre todos os agentes do GER, Tassio, para invadir uma favela e libertar um refém que estava detido em um cativeiro, sendo naquele momento guardado por apenas um dos sequestradores. Qual não foi sua surpresa quando Tassio o levou para o estacionamento e entrou em uma caminhonete 4x4 importada e blindada. Lá dentro, havia um verdadeiro arsenal, com fuzil, pistola importada, equipamentos que Maruan havia visto apenas em filmes de Hollywood ou em pesquisas na internet. Ao ver sua cara de 
HOMENS EM ARMAS: A TRAJETÓRIA DO POLICIAL CIVIL PARA ANÁLISE SOBRE VIDA...

Rodrigo Guimarães Motta, Maria Amélia Jundurian Corá

perplexidade, Tassio riu e explicou: "Todos aqui, se quiserem sobreviver, têm que ter os melhores equipamentos. Não utilizamos o que a polícia nos oferece, cada um compra aqui tudo de que precisa". Sem dar maiores explicações, saíram os dois. Com segurança, Tassio assumiu desde o princípio o comando da situação. Se Maruan duvidava da competência da equipe do GER, aquela dúvida acabou muito rapidamente. Tassio invadiu a casa, imobilizou o sequestrador e logo encontrou o aposento onde estava o sequestrado, importante empresário da capital. A partir desse momento, Maruan passou a ter, pelo menos no quesito de enfrentamento com os criminosos, uma referência, alguém que o inspirava: Tassio.

Ser parceiro de Tassio, entretanto, não foi tão positivo quanto Maruan imaginava, após aquela ocorrência. Se, do lado profissional, ele se tornou muito mais competente pela sua convivência com Tássio, problemas surgiram por outro lado. Todos os dias, após treinar com suas armas próprias, Tassio almoçava em alguma churrascaria da moda junto com os outros colegas do GER. Maruan simplesmente não tinha a menor condição financeira de manter um padrão de vida desses. Com o tempo, percebeu que todos os integrantes desse grupo eram policiais e empresários. Oriundos de famílias de classe média alta, entraram na polícia por vocação, por buscarem a mesma adrenalina que Maruan também almejava. Mas, com bons contatos, boa formação e percebendo a necessidade de se equipar de modo melhor, os integrantes do GER abriam suas próprias empresas de segurança.

Alguns faziam segurança corporativa, outros eram especialistas em segurança pessoal para empresários e executivos. Tássio, que não era dos maiores policiais empresários do grupo, tinha 50 seguranças particulares em sua empresa, todos policiais civis ou militares, que assim também, em menor escala, complementavam sua renda. Com o dinheiro arrecadado, as lendas do GER adquiriam equipamentos que fariam inveja a qualquer exército ou polícia do mundo. Evidentemente que tudo isso, equipamentos, empresas, era irregular. Quando comentou isso, Tassio olhou Maruan com desprezo: "E qual a sua sugestão? Ser morto por um menor de idade armado com um fuzil? E pense bem antes de falar qualquer coisa com alguém de fora. Ninguém mexe com um policial do GER". Maruan percebeu que Tássio era muito mais do que um policial do GER. Ele comandava o grupo, tinha muito influência sobre todos os policiais, e mesmo Antônio não questionava os caminhos do subordinado. Aos poucos, Maruan saiu da esfera de influência de Antônio e passou a ser um dos aliados de Tássio.

Essa afirmação veemente não se realizou no período em que Maruan esteve no GER. Após quase dois anos na função, Antônio foi demitido de sua função pelo mesmo diretor que o havia nomeado para o posto, seu amigo de infância. O motivo era da mais alta relevância: a pedido de um deputado, aliado do governador e presidente da Assembleia Legislativa, o novo diretor do GER seria seu cunhado. Maruan não sofreu com a saída de seu antigo protetor, pois já era um homem de Tássio e pretendia continuar no GER, mesmo que este estivesse sob nova direção. Mas as coisas não seriam tão simples assim.

O novo chefe do GER, Manoel, que nunca havia passado por nenhuma das equipes de elite da Polícia Civil, inseguro em sua nova posição, começava as reuniões com seu time com uma frase motivacional: "O único galo deste galinheiro aqui sou eu". Todos mal podiam conter o riso. O pobre chefe era tratado com desprezo por todos, menos por Maruan, que também não era aceito pelos outros totalmente, em função da disparidade socioeconômica. Quem mais desprezava Manoel era a lenda das lendas, Tássio. Esse dia a dia policial, repleto de ações de enfrentamento com bandidos perigosos e com alta carga de tensão interna, absorvia toda a energia de Maruan, que praticamente deixou de se relacionar com sua família. Ainda que estivesse distante de pais e irmãos, nunca deixou de depositar a sua parte da ajuda mensal para o sustento dos pais. O relacionamento entre eles era essencialmente financeiro.

Certo dia, logo pela manhã, Manoel chamou todos os integrantes do GER para uma reunião. O clima estava pesado e, quando entraram, na sala já estavam Manoel, com ar triunfante, e Tassio, 
HOMENS EM ARMAS: A TRAJETÓRIA DO POLICIAL CIVIL PARA ANÁLISE SOBRE VIDA...

Rodrigo Guimarães Motta, Maria Amélia Jundurian Corá

visivelmente furioso. Manoel não queria perder tempo e comunicou a todos a novidade: Tassio, a partir daquele dia, não fazia mais parte do GER, fora transferido para uma delegacia afastada. Por isso, ele contava, mais do que nunca, com o apoio de todos os demais integrantes do grupo. Após minutos de silêncio, um a um, os integrantes do GER pediram sua transferência para um atônito Manoel. No final, apenas Maruan não havia pedido para sair. Todos aqueles policiais, milionários, lendas da corporação, olhavam fixamente para o mais jovem integrante do grupo. Suspirando fundo, Maruan percebeu que não tinha outra escolha. Ou faria a coisa certa ou seria um pária por todos os anos que faltavam para sua aposentadoria na polícia. Levantou-se e disse uma frase curta: "Peço também minha transferência". Naquele dia, o GER ficou sem nenhum dos seus integrantes, e sua eficácia no combate a criminosos demoraria anos para ser recuperada. Para Maruan, aquilo era uma tristeza, mas, afinal, com a experiência adquirida e em um posto de menor responsabilidade, ele poderia pensar em dar o próximo passo com Renata.

\section{O GARRA}

Sim, Maruan estava namorando e pretendia se casar com Renata, uma jovem que conhecera na academia onde se exercitava. Mas, com o salário que recebia, e tendo que organizar sua própria casa e ainda auxiliar seus pais, ele poderia muito bem aproveitar essa saída do GER para montar a sua própria empresa de segurança. Ainda mais que Renata era administradora de empresas e poderia auxiliá-lo na gestão do negócio. Seguiria, assim, os passos de Tassio e das outras lendas com quem convivera no GER. Como ex-integrante do GOE e do GER, foi designado para outro grupo de elite, o Garra - grupo armado de repressão a roubos e assaltos, que, além de apoiar os policiais do Departamento de Investigações Criminais (DEIC), faz também rondas rotineiras. Ainda que tenha conseguido efetivamente se casar e abrir sua empresa de segurança logo em seu primeiro ano no Garra, era desalentador para Maruan fazer seu trabalho na Zona Norte de São Paulo em uma viatura caindo aos pedaços, com escassez de recursos até para a gasolina. De Tássio e dos demais colegas do GER, se afastou completamente, pois estes foram todos remanejados para delegacias distantes uma da outra.

Comparada com a do GER, a situação era desanimadora. Para piorar, nas delegacias que frequentava, conheceu alguns delegados e agentes que tinham o mesmo padrão de vida dos policiais do GER, ainda que não os mesmos equipamentos. Ainda que jamais tenha recebido uma proposta para se unir a algum desses emergentes das delegacias, ele e todos os demais sabiam como esses almoços eram pagos. Era a corrupção, motivada por péssimos salários e nenhum controle por parte do Estado.

O tempo passou, e Renata, grávida do primeiro filho do casal, começou a pedir para Maruan deixar o Garra e assumir um posto mais tranquilo em alguma delegacia. Afinal, ele já estava havia cinco anos nos grupos de elite da polícia, tinha uma pequena e próspera empresa e, em breve, teria um filho, além dos pais idosos, que nunca deixou de auxiliar. Tudo isso era verdade, e Maruan também estava desgastado por causa da falta de apoio da instituição, das péssimas condições de trabalho e da corrupção que via grassar na corporação. Mas, ainda assim, era um legítimo policial de elite e não estava disposto a abrir mão dos seus sonhos de criança, da adrenalina de ouvir a sirene na viatura. Só quando, em uma ocorrência de rotina, pela primeira vez, recebeu um tiro, no braço, foi que realmente caiu essa ficha, e ele pediu sua transferência. Afinal, tinha toda uma vida fora da polícia, era só esperar mais 15 anos para se aposentar, então por que continuaria se arriscando?

\section{Na delegacia}

Acordar todos os dias para ir trabalhar na delegacia era um desprazer que só fazia piorar ano após ano. A rotina da delegacia, onde ele passava $70 \%$ do tempo realizando trabalhos burocráticos e atendendo a vítimas de furtos ou de batidas de carro que queriam fazer um boletim de ocorrência, era o oposto do que ele havia realizado no GOE, GER e Garra. Um trabalho entediante, em que ele se 
HOMENS EM ARMAS: A TRAJETÓRIA DO POLICIAL CIVIL PARA ANÁLISE SOBRE VIDA...

Rodrigo Guimarães Motta, Maria Amélia Jundurian Corá

sentia mais como um administrador de conflitos do que como o policial com que sonhava quando criança. Muitas vezes, era agredido verbalmente por cidadãos que estavam em uma situação de muita tensão emocional. E, sem as fardas dos grupos especiais, começou a perceber que era visto com desprezo e medo pela população, tanto por aqueles que moravam próximo da sua casa quanto por aqueles que pediam seu auxílio na delegacia. O medo ele podia entender, devido à publicidade dada a casos de má conduta em ação, como aquele que ocorrera com seu antigo colega Rafael. O desprezo acontecia pela fama de corrupta da polícia. Enquanto os grupos especiais passavam mais ou menos incólumes com essas acusações, o policial na delegacia era inevitavelmente considerado um corrupto, que só fazia a engrenagem trabalhar mediante o recebimento de benefícios pessoais. Nessas situações, ele se lembrava da dona da padaria próxima à casa dos seus pais, Débora. A frustração por essa situação era tão grande que já não treinava mais, engordou 20 quilos, bebia depois do expediente. Na sua vida, o que o fazia seguir adiante era a proximidade da sua esposa e filho e a prosperidade da pequena firma de segurança. Da polícia, só esperava a aposentadoria, que deveria chegar em pouco mais de 10 anos. Pelo menos, a delegacia onde trabalhava era próxima de casa e ele podia passar mais tempo com sua família. Mas, em breve, isso também mudaria para pior.

Era um dia frio e chuvoso em São Paulo, e Maruan deveria sair com a velha viatura disponível para atender uma ocorrência que ocorreu na região. Ao tentar ligar a viatura, o motor não respondeu. $\mathrm{O}$ carro inútil não permitiu que ele atendesse a ocorrência. Indignado, reclamou com outro agente que estava na delegacia, José, das péssimas condições de trabalho. Um comentário feito em um momento de frustração, motivado por mais um dos muitos problemas que Maruan enfrentou em sua carreira. José, todavia, que era um dos agentes que enriqueciam de modo ilícito dentro da delegacia, detectou ali uma oportunidade de se livrar do honesto e frustrado Maruan.

Na primeira oportunidade, comentou com a delegada Maricy que o agente Maruan estava insatisfeito com suas condições de trabalho e que falava mal da delegacia para os agentes. Maricy, que nunca gostou de Maruan, por achá-lo prepotente, por ter participado dos grupos especiais, e também porque ela própria fazia parte do esquema de corrupção instalado na delegacia, viu ali uma oportunidade de se livrar de Maruan de uma vez por todas. Queixou-se do subordinado com as pessoas certas, e finalmente conseguiu a transferência dele para uma delegacia situada em Guarulhos. Quando recebeu o documento, nem se deu ao trabalho de falar pessoalmente com Maruan, pediu para José dar-lhe a notícia.

Maruan recebeu aquela péssima notícia com surpreendente resignação. Era apenas mais uma situação, entre tantas pelas quais passara, na qual fora prejudicado por motivos alheios a sua competência profissional. Hoje, faltando apenas seis anos para sua aposentadoria, muito acima do peso, trabalha na delegacia de Guarulhos com as mesmas péssimas condições a que está acostumado. Para chegar lá, são mais de duas horas no trânsito na ida e o mesmo tempo na volta. E, quando chega, é aquele trabalho burocrático com o qual ele jamais sonhou. Já muito experimentado, toma todo o cuidado para não dividir sua frustração com ninguém. É um policial sisudo, que cumpre suas obrigações e pouco interage com os colegas. Amigos, não tem no trabalho. Mas sabe que esses seis anos passarão rápido, e para ajudá-lo a passar esse tempo com alguma alegria ele conta com a esposa, seus dois filhos pequenos e com os pais, já bem velhinhos. Uma vez por ano, no Natal, toda a família se reúne e ele, com uma certa inveja, observa as condições financeiras muito mais prósperas que seus irmãos possuem. Estes não escondem o desconforto de ver seu irmão mais novo tão amargurado com a vida que leva. Mas o admiram, e, certa vez, sua irmã expressou isso, pela forma estoica com que ele enfrentou a adversidade em sua carreira e pelo fato de sempre ter ajudado os pais, mesmo tendo o orçamento bem mais apertado do que eles. São apenas seis anos, e, quando se aposentar, ele poderá se dedicar a sua querida família e a sua empresa de segurança, que, se não é uma grande empresa, assegura uma renda quatro vezes superior ao seu salário como agente de polícia. Qual o significado que a carreira de Maruan na Polícia Civil teve para ele em cada um dos desafios por que passou? Qual influência as disputas de poder que aconteceram na polícia tiveram na sua carreira? 